Joyful Learning Journal

\title{
PENDIDIKAN KARAKTER DAN REWARD DALAM MENGUATKAN MOTIVASI BELAJAR ERA REVOLUSI INDUSTRI 4.0
}

\author{
Ferindra Sari , A. Busyairi
}

Jurusan Pendidikan Guru Sekolah Dasar, Fakultas Ilmu Pendidikan, Universitas Negeri Semarang, Indonesia

\begin{tabular}{|c|c|}
\hline Info Artikel & Abstrak \\
\hline $\begin{array}{l}\text { Sejarah Artikel: } \\
\text { Diterima Apeil } 2020 \\
\text { Disetujui Mei } 2020 \\
\text { Dipublikasikan Juni } \\
\mathbf{2 0 2 0}\end{array}$ & $\begin{array}{l}\text { Penelitian ini bertujuan untuk mendeskripsikan pendidikan karakter dan reward dalam menguatkan motivasi } \\
\text { belajar siswa era revolusi industri 4.0. Subjek penelitian ini adalah kepala sekolah, guru kelas dan siswa IV SDN } \\
\text { Purwosari } 02 \text { Kota Semarang. Penelitian ini merupakan penelitian kualitatif dengan jenis deskriptif. Teknik } \\
\text { pengambilan data menggunakan observasi partisipan, wawancara, angket, dan dokumentasi. Hasil penelitian } \\
\text { menunjukkan pendidikan karakter secara perlahan mampu menanamkan dan membentuk pembiasaan baik yang } \\
\text { sesuai dengan } 18 \text { nilai karakter bangsa. Faktor pendukung pendidikan karakter dalam menguatkan motivasi belajar } \\
\text { siswa adalah melalui pembisaan karakter luhur. Motivasi belajar siswa juga tumbuh melalui reward, terutama saat } \\
\text { proses pembelajaran, reward lebih memotivasi siswa untuk meningkatkan prestasi belajarnya. Simpulan penelitian } \\
\text { ini adalah pendidikan karakter dan reward mampu menguatkan motivasi belajar siswa era revolusi industri } 4.0 \text {. } \\
\text { Reward yang diimbangi dengan pembiasaan pendidikan karakter, siswa mampu memberikan dorongan kepada } \\
\text { temannya agar motivasi belajar di kelas menguat sehingga siswa aktif dalam pembelajaran. }\end{array}$ \\
\hline
\end{tabular}

Abstract

The purpose of this research was to describe character education and reward in strengthening the motivation of studying 4.0 industrial revolution era students. The subject of this study were principal, class teachers and fourth grade students of Purwosari State Elementary School 02 Semarang. This research was qualitative study with a kind of descriptive. Data retrieval techniques used participant observation, interviews, questionnaires, and documentation. The study results showed that character education was slowly able to instill and shape a good culture that corresponds to the 18 character values of the nation. Supporting factor character education in strengthening the motivation for learning a student is through habituation of sublime characters. The motivation for study the student also in the past form through reward, especially when the learning process, motivates the student to increase his or her learning attainment. The conclusions of this study was character education and reward capable of strengthening the motivation for studying 4.0 industrial revolution students. Reward balanced with character education accustomed, the student was able to encourage his or her friend so that motivation for learning in the classroom strengthen with the result that the student was active in learning.

(C) 2020 Universitas Negeri Semarang

Alamat korespondensi:

Purwosari RT 04 RW 03 Mijen Kota Semarang

ISSN 2252-6366

E-mail: ferindrasari7@gmail.com 


\section{PENDAHULUAN}

Pendidikan menjadi salah satu hak dan kewajiban bagi seluruh warga Negara Indonesia. Hal ini tercantum dalam Undang-Undang Dasar Negara Kesatuan Republik Indonesia 1945 Pasal 31. Tujuan pendidikan Indonesia sebagaimana diperjelas dalam Undang-Undang Sistem Pendidikan Naisonal (UU Sisdiknas No. 20 Tahun 2003). Selain itu, Pemerintah telah melegalkan Peraturan Presiden Nomor 87 Tahun 2017 tentang Penguatan Pendidikan Karaketer Bangsa.

Tingkat keberhasilan pelaksanaan pendidikan karakter di suatu sekolah dilihat dengan membandingkan kondisi awal dan waktu tertentu setelah melaksanakan program tertentu yang diketahui dari indikator keberhasilannya (Wibowo, 2012:98). Reward and Punishment adalah metode pembelajaran interaktif antara guru dan peserta didik yang menerapkan sistem pemberian hadiah dan hukuman bagi peserta didik, (Muliawan dalam Kusyairi Jurnal Pendidikan Fisika Vol.6 No.2 2018). Motivasi merupakan salah satu faktor yang ikut menentukan keberhasilan anak didalam belajar, Rifa'i (2016:103). Haqqi (2019:8) mengungkapkan bahwa revolusi industri (RI) Revolusi industri diawali dengan periode industrialisasi besar-besaran tahun 1700an hingga 1800an. Revolsui industri kedua berlangsung antara 1850-1914. Dilanjutkan dengan revolusi industri ketiga terjadi sekitar tahun 1950, revolusi industri ketiga dijadikan sebagai pijakan revolusi industri 4.0 sekarang ini. Society 5.0 adalah konsep yang lahir untuk menanggapi fenomena yang hadir akibat revolusi industri 4.0. Era Revolusi Industri 4.0 memiliki banyak dampak bagi pendidikan di Indonesia. Misalnya memengaruhi kesenjangan kesetaraan/kesetaraan gender dalam pendidikan, (Linh dalam International Journal of Engineering Science Invention Vol. 8 No. 6 tahun 2019).

Berdasarkan laporan Programme for International Student Assessment (PISA) penilaian peringkat pendidikan Indonesia di dunia tahun 2018 menunjukkan bahwa matematika skor 379 , membaca skor 371 dan sains skor 396, skor ini jauh menurun dibanding di tahun 2015, (Kompasiana, diakses Minggu, 8 Desember 2019 Pukul 06.10). PISA pertama kali diselenggarakan pada tahun 2000 untuk membantu negara-negara dalam mempersiapkan sumber daya manusia agar memiliki kompetensi yang sesuai dengan yang diharapkan dalam pasar internasional (Pratiwi Jurnal Pendidikan dan Kebudayaan Vol.4 No.1 2019). International Civic and Citizinship Education study (ICCS) menyatakan bahwa perkembangan pendidikan karakter merupakan respon dari persiapan generasi muda dalam menghadapi abad 21, (Ahmadi dkk Jurnal Penelitian Pendidikan vol.34 no.2 tahun 2017 hal 128).

Merujuk pada studi yang dilakukan ICCS dan PISA, juga peneliti temui di kelas IV SDN Purwosari 02 dengan jumlah 26 terdiri atas 15 siswa dan 11 siswi yang memiliki masalah motivasi belajar sehingga berpengaruh pada nilai siswa. Sedikit siswa yang memiliki motivasi belajar tinggi sehingga nilainya memuaskan, namun masih banyak siswa motivasi belajarnya rendah sehingga nilainya masih banyak di bawah 70. Selain itu pengembangan pendidikan karakter juga perlu ditingkatkan agar mampu merubah siswa yang mulanya memiliki motivasi belajar rendah mampu merubah dirinya agar prestasi belajarnya tinggi.

Penelitian yang relevan dengan permasalahan yang diangkat peneliti adalah penelitian oleh Dini Palupi Putri dalam Jurnal Pendidikan Dasar Vol. 2 No. 1 halaman 37-50 tahun 2018 tentang peran keluarga, guru dan masyarakat sekitar dalam perkembangan karakter sangat penting di era digital. Selanjutnya jurnal oleh Silvia Anggraini dkk dalam Jurnal Mimbar PGSD Undiksha Vol. 7 No. 3 halaman 221-229 tahun 2019 tentang analisis Dampak Pemberian Reward and Punishment bagi Siswa SD Negeri Kaliwiru Semarang. Jurnal selanjutnya oleh Hendra Suwardana dalam Jurnal Revolusi Industri 4.0 Berbasis Revolusi Mental Vol.1 No.2 halaman 102-110 tahun 2017.

Merujuk pada observasi dan wawancara awal serta penelitian sebelumnya yang relevan, peneliti mendeskripsikan dan mengkaji lebih intens tentang pelaksanaan pendidikan karakter dan reward dalam menguatkan motivasi belajar siswa era revolusi industri 4.0 yang telah berdampak pada kehidupan generasi muda saat ini.

\section{METODE PENELITIAN}

Dalam penelitian ini, metode penelitian yang digunakan peneliti adalah metode penelitian deskriptif kualitatif. Siswa kelas IV SDN Purwosari 02 dijadikan sebagai sumber data primer utama karena siswalah yang menjadi objek, kepala sekolah, guru kelas IV dan orang tua siswa. Dalam penelitian ini sumber data sekunder yang digunakan meliputi dokumen-dokumen pendukung, foto atau video. Dalam penelitian kualitatif disampaikan oleh Lofland dan Lofland dalam Moleong (2016: 157) bahwa sumber data utama dalam penelitian kualitatif adalah kata-kata dan tindakan. Selebihnya adalah data tambahan seperti dokumen dan lain-lain.

Teknik pengumpulan data berupa observasi, wawancara, angket, dokumentasi dan catatan lapangan. Setelah menentukan teknik pengumpulan data, peneliti menyusun instrumen yang disesuaikan dengan intrumen penelitian. Observasi dilakukan tiga kali secara bertahap, wawancara yang digunakan adalah semiterstruktur, serta penyebaran angket pendidikan karakter, reward dan motivasi belajar siswa. Angket yang digunakan adalah angket tertutup yaitu sudah disediakan jawabannya, dengan pilihan jawaban selalu, sering, kadang-kadang dan tidak pernah. Pengujian keabsahan data menggunakan uji kredibilitas dan uji konfirmabilitas. Uji kredibilitas yang digunakan peneliti adalah triangulasi (sumber, teknik, waktu) dan cakupan bahan referensi. Teknik analisis data menggunakan model Miles and Huberman, aktivitas dalam analisis data yaitu 
data reduction, data display, dan conclusions drawing/verifying.

\section{HASIL DAN PEMBAHASAN}

\section{Pendidikan Karakter kelas IV SDN Purwosari 02}

Tabel 1. Hasil Observasi Pendidikan karakter kelas IV SDN Purwosari 02

\begin{tabular}{|c|c|c|c|c|c|c|}
\hline \multirow[t]{3}{*}{ Indikator } & \multicolumn{2}{|c|}{ Observasi } & \multicolumn{4}{|c|}{ Observasi I Observasi III } \\
\hline & \multicolumn{2}{|c|}{ Deskripto } & \multicolumn{2}{|c|}{ Deskriptor } & \multicolumn{2}{|c|}{ Deskriptor } \\
\hline & $\overline{\text { Munc }}$ & Tida & $\overline{\text { Munc }}$ & Tida & $\overline{\text { Mun }}$ & IC Tidak \\
\hline Religius & 2 & 1 & 2 & 1 & 3 & 0 \\
\hline $\begin{array}{l}\text { Peduli } \\
\text { lingkung } \\
\text { a }\end{array}$ & 1 & 5 & 3 & 3 & 6 & 0 \\
\hline $\begin{array}{l}\text { Gemar } \\
\text { membac } \\
\text { a }\end{array}$ & 1 & 5 & 3 & 3 & 5 & 1 \\
\hline
\end{tabular}

Merujuk data observasi yang dilakukan sebanyak tiga kali secara bertahap terlihat adanya peningkatan setiap indikatornya. Misalnya indikator peduli lingkungan terlihat bahwa pertemuan pertama siswa belum memiliki kesadaran untuk menjaga kebersihan lingkungan, masih siswa ada membuang sampah sembarangan. Pada pertemuan ketiga siswa sudah mampu membedakan jenis sampah sebelum membuangnya. Hal tersebut dibuktikan saat observasi dengan siswa bekerja sama membersihkan halaman sekolah dan mengumpulkan sampah sesuai jenisnya. Hasil wawancara dengan perwakilan orang tua kelas IV menyatakan bahwa anak di rumah diizinkan untuk menggunakan handphone sesuai batas waktu yang diberikan orang tua dan dengan pengawasan orang tua. Siswa menggunakan handphone untuk bermain game, komunikasi dengan teman melalui aplikasi whatsapp (WA) dan mencari referensi materi dengan jaringan internet untuk menambah sumber bahan belajar.

\section{Reward Siswa Kelas IV SDN Purwosari 02}

Tabel 2. Hasil Observasi Reward kelas IV SDN Purwosari 02

\begin{tabular}{|c|c|c|c|c|c|c|}
\hline \multirow[t]{4}{*}{ Indikator } & \multicolumn{2}{|c|}{ Observasi } & \multicolumn{2}{|c|}{ Observasi } & Obse & rvasi I \\
\hline & \multicolumn{2}{|c|}{ Deskripto } & \multicolumn{2}{|c|}{ Deskripto } & Desk & $\overline{\text { kriptor }}$ \\
\hline & \multicolumn{3}{|c|}{ Munc Tida Munc } & Tida & Munc & $\begin{array}{l}\text { Tida } \\
\text { Mun }\end{array}$ \\
\hline & & Iunc & & Munc & & \\
\hline $\begin{array}{l}\text { Ungkapan } \\
\text { pujian }\end{array}$ & 3 & 0 & 3 & 0 & 3 & \\
\hline $\begin{array}{l}\text { Gerak } \\
\text { isyara }\end{array}$ & 1 & 0 & 1 & 0 & 1 & \\
\hline $\begin{array}{l}\text { Pendekatan } \\
\text { oleh guru }\end{array}$ & 0 & 2 & 2 & 0 & 2 & \\
\hline Penghargaa & 1 & 0 & 1 & 0 & 1 & \\
\hline
\end{tabular}

$\mathrm{n}$

dengan

sentuhan

Kegiatan

menyenang

$\mathrm{k}$

Simbol/ben

d

\begin{tabular}{llllll}
0 & 1 & 0 & 1 & 1 & 0 \\
0 & 2 & 0 & 2 & 1 & 1 \\
\hline
\end{tabular}

Merujuk pada data observasi yang dilakukan sebanyak tiga kali terlihat adanya peningkatan pada setiap indikatornya. Beberapa kekurangan tersebut pada indikator penghargaan dengan kegiatan menyenangkan dan penghargaan berupa simbol atau benda. Kurangnya penghargaan dengan kegiatan menyenangkan salah satunya terlihat bahwa guru belum menggunakan media pembelajaran yang mampu membantu menguatkan motivasi belajar siswa. Merujuk wawancara dengan siswa penghargaan berupa simbol atau benda jarang diberikan, guru lebih sering memberikan reward berupa pujian dan pendekatan dengan siswa. Merujuk wawancara dengan guru kelas IV terlihat bahwa reward mampu menguatkan motivasi belajar siswa. Hal ini terlihat dengan adanya siswa lain yang termotivasi setelah guru memberikan reward pada salah satu siswa. Pemberian reward mampu membuat siswa antusias mengikuti pembelajaran di kelas. Perlu ada kerja sama antara orang tua dan guru dalam membantu anak menguatkan motivasi belajarnya salah satunya dengan pemberian hadiah baik berupa benda maupun berupa ucapan selamat jika anak memperoleh nilai bagus. Namun tidak semua siswa tertarik dengan reward hal ini terlihat bahwa masih ada siswa yang tidak antusias belajar meskipun guru sudah menunjukkan reward yang aan diberikan. Perlu adanya pemberian reward yang sesuai dengan kebutuhan siswa agar mampu menarik perhatian siswa saat mengikuti pembelajaran di kelas dan mampu memahami materi pelajaran sehingga nilai yang diperoleh memuaskan.

\section{Penguatan Motivasi Belajar Siswa Kelas IV SDN Purwosari 02}

Tabel 3. Hasil Observasi Motivasi belajar siswa kelas IV SDN Purwosari 02

\begin{tabular}{|c|c|c|c|c|c|c|}
\hline \multicolumn{7}{|l|}{ Indikato } \\
\hline \multirow[t]{5}{*}{$r$} & \multicolumn{4}{|c|}{ Observasi } & $\mathrm{Obs}$ & ervasi II \\
\hline & \multirow{2}{*}{\multicolumn{2}{|c|}{ Deskriptor }} & \multirow{2}{*}{\multicolumn{2}{|c|}{ Deskriptor }} & \multicolumn{2}{|c|}{ Deskripto } \\
\hline & & & & & $r$ & \\
\hline & \multirow[t]{2}{*}{ Munc } & \multirow{2}{*}{\multicolumn{2}{|c|}{$\begin{array}{l}\text { Tida Munc } \\
\text { Munc }\end{array}$}} & \multicolumn{2}{|c|}{ Tida Mun } & Tidak \\
\hline & & & & Munc & 1 & Muncu \\
\hline $\begin{array}{l}\text { Perasaan } \\
\text { senang }\end{array}$ & 2 & 1 & 2 & 1 & 3 & 0 \\
\hline $\begin{array}{l}\text { Kemauan } \\
\text { Kesadara }\end{array}$ & 0 & 2 & 2 & 0 & 2 & 0 \\
\hline $\begin{array}{l}\mathrm{n} \\
\text { dalam } \\
\text { diri }\end{array}$ & 1 & 2 & 2 & 1 & 3 & 0 \\
\hline
\end{tabular}




\begin{tabular}{|c|c|c|c|c|c|c|}
\hline $\begin{array}{l}\text { Doronga } \\
\mathrm{n} \\
\text { orang tua }\end{array}$ & 1 & 0 & 1 & 0 & 1 & 0 \\
\hline $\begin{array}{l}\text { Pemberia } \\
\mathrm{n} \\
\text { reward } \\
\text { Pemberia }\end{array}$ & 0 & 1 & 0 & 1 & 1 & 0 \\
\hline $\begin{array}{l}\text { n } \\
\text { tugaso } \\
\text { guru }\end{array}$ & 0 & 1 & 0 & 1 & 0 & 1 \\
\hline $\begin{array}{l}\text { Kegiatan- } \\
\text { kegiatan } \\
\text { sekolah }\end{array}$ & 1 & 0 & 1 & 0 & 1 & 0 \\
\hline
\end{tabular}

Merujuk pada observasi yang dilakukan sebanyak tiga kali terdapat peningkatan pada setiap indikatornya. Namun ada indikator yang belum tercapai yaitu pemberian tugas oleh guru. Pada observasi yang telah dilakukan terlihat bahwa guru belum memberikan kesempatan kepada siswa untuk menemukan masalah sendiri dan memecahkannya. Guru biasanya meminta siswa mengerjakan soal yang ada pada buku materi yang dimiliki siswa dan tugas yang sudah disiapkan guru. Merujuk hasil wawancara dengan orang tua siswa, kurangnya waktu untuk mendampingi anak belajar di rumah sehingga orang tua mendaftarkan anak di Bimbingan Belajar (Bimbel). Hal tersebut menjadi salah satu dukungan orang tua pada anak agar memiliki kesadaran untuk belajar.

\section{Pendidikan Karakter dan Reward dalam Menguatkan Motivasi Belajar Siswa Era Revolusi Industri 4.0 Kelas IV SDN Purwosari 02}

Era Revolusi Industri 4.0 telah merambah ke berbagai aspek kehidupan, tidak terkecuali pendidikan. Peluang pemanfaatan teknologi ini jika dapat dimanfaatkan secara optimal untuk meningkatkan motivasi belajar peserta didik dalam rangkaian meningkatkan kualitas pendidikan di Indonesia (Muhasim dalam Jurnal Studi Keislaman dan Ilmu Pendidikan Vol 5(2) tahun 2017).

Kecanggihan teknologi juga berdampak baik bagi siswa jika pemanfaatannya tepat. Teknologi dapat dimanfaatkan untuk pencarian literasi-literasi penambahan ilmu pengetahuan dalam pembelajaran. Siswa bisa menelusuri google, yahoo dan situs lainnya dalam mencari artikel, jurnal, makalah, dan buku elektronik untuk keperluan tugas sekolahnya. Tetapi teknologi juga tidak terlepas dari dampak negatif, sehingga dalam pemanafaatan teknologi tersebut perlu adanya bimbingan dan pengawasan dari orang dewasa. Selain kecanggihan teknologi, era revolusi industri (RI) 4.0 berdampak pada karakter siswa. Dalam siaran televisi sering diberitakan adanya siswa yang melakukan bullying melalui akun media sosial. Selain itu tontonan yang kurang mendidik semakin mudah diakses oleh generasi digital. Generasi digital saat ini memiliki sifat yang tidak ingin dikekang dan lebih suka menikmati kebebasan.

Hal tersebut juga terjadi pada siswa kelas IV era RI 4.0 di SDN Purwosari 02 dari hasil observasi terlihat masih ada siswa yang melakukan tindakan bullying secara langsung dengan mengejek nama orang tua siswa. Selain itu siswa masih ada yang tidak menaati tata tertib dengan berperilaku bebas saat ditinggal guru dengan diberikan tugas di kelas. Siswa tersebut terlihat berjalan-jalan dan mengganggu temannya yang sedang bersungguhsungguh mengerjakan tugas. Saat berinteraksi, masih ada siswa yang menggunakan bahasa Jawa Ngoko untuk berkomunikasi dengan guru atau penjaga sekolah. Hal ini sejalan dengan Amri dalam Racmadyanti Jurnal Pendidikan Sekolah Dasar Vol 3(2) tahun 2017 bahwa manusia yang berkarakter baik adalah manusia yang berusaha untuk melakukan hal-hal terbaik bagi Tuhan, dirinya, sesama lingkungan, bangsa dan negara serta dunia pada umumnya serta mengoptimalkan potensi (pengetahuan) dirinya disertai kesadaran emosi dan motivasinya.

Motivasi adalah bagian kompleks dari psikologi manusia yang mencerminkan pada siswa bagaimana kemauan dalam belajar, memanfaatkan waktu untuk belajar, gigih dalam belajar serta bagaimana mereka mengatasi hambatan dalam proses belajar, (Bakar International Journal of Asian Social Science Vol.4 No.6 tahun 2014). Hasil observasi memperlihatkan bahwa motivasi belajar siswa secara bertahap meningkat. Penanaman nilai karakter pada siswa menjadikannya mengerti tindakan baik dan buruk sehingga bisa menerapakannya dalam kehidupan sehari-hari. Siswa juga menjadi bersemangat jika reward yang diperolehnya mampu memotivasi siswa lain di SDN Purwosari 02. Meskipun masih ada siswa yang kurang antusias dan tertarik pada reward yang diberikan guru sehingga tidak merespon pertanyaan yang diberikan guru. Hasil tersebut didukung oleh penelitian Raihan dalam Journal of Islamic Education vol. 2 no. 1 tahun 2019 bahwa reward and punishment dalam bentuk pujian, gerakan tubuh, hadiah, tepuk tangan senyuman, nilai harian, dan sering menyebut namanya mampu menjadikan siswa semakin termotivasi mengikuti proses pembelajaran.

Faktor pendukung dan penghambat pendidikan karakter dan reward dalam menguatkan motivasi belajar siswa era revolusi industri 4.0 Kelas IV SDN Purwosari 02

Faktor pendukung pendidikan karakter dalam menguatkan motivasi belajar adalah kerjasama antarwarga sekolah dan orang tua siswa. Sedangkan faktor penghambatnya adalah siswa yang susah diberikan arahan biasanya disebabkan oleh latar belakang siswa. Meskipun sudah diberi kebiasaan-kebiasaan baik di sekolah, tetapi orang tua dan masyarakat di lingkungan rumah harus memberikan contoh pembiasaan baik pula agar pelaksanaan pendidikan karakter mendapatkan haisl yang maksimal, (Priambudi Jurnal Prodi Teknologi Pendidikan Vol.7 No.2 tahun 2018).

Faktor yang mempengaruhi pemberian reward kurang optimal adalah masih ada siswa yang tidak percaya diri dan memiliki keberanian untuk melakukan suatu hal yang diinstruksikan guru dalam proses pembelajaran, (Vinorita 
Economic Education Analysis Journal Vol.7 No.2 tahun 2018).

Merujuk wawancara dengan kepala SDN Purwosari 02 bahwa faktor pendukung reward dalam menguatkan motivasi belajar siswa adalah siswa lebih semangat belajar setelah ada teman yang mendapatkan reward. Faktor penghambatnya yaitu siswa kurang percaya diri, malu dan kurang mandiri. Hal tersebut didukung dengan data wawancara guru kelas bahwa faktor pendukung reward dalam menguatkan motivasi belajar siswa adalah mengubah cara belajar dengan menggunakan media pembelajaran dan bentuk reward yang mampu memotivasi siswa lain. Sedangan faktor penghambatnya yaitu masih ada siswa yang kurang tertarik dengan adanya.

\section{SIMPULAN}

Simpulan penelitian ini meliputi pendidikan karakter dapat dijadikan untuk menguatkan motivasi belajar siswa dengan pembiasaan nilai-nilai karakter. Pendidikan karakter juga menanamkan dan mengembangkan karakter-karakter luhur sehingga siswa dapat menerapkan dalam kehidupannya. Penguatan berupa penghargaan positif (reward) sebagai upaya guru dalam menguatkan motivasi belajar siswa. Terdapat peningkatan perhatian siswa terhadap pelajaran sehingga merangsang dan meningkatkan motivasi belajarnya. Siswa yang sudah menguat motivasi belajarnya berdampak baik terhadap prestasi belajarnya. Faktor pendukung berhasilnya pendidikan karakter dan reward dalam menguatkan motivasi belajar siswa era revolusi industri 4.0 adalah siswa dan kerja sama antara pihak sekolah dengan orang tua.

\section{UCAPAN TERIMA KASIH}

Peneliti mengucapkan terima kasih kepada kedua orang tua yang selalu memberikan dukungan kepada peneliti. Dosen pembimbing, Drs. A. Busyairi, M.Ag. serta mitra bestari Desi Wulandari, S.Pd., M.Pd. dan Drs. Isa Ansori, M.Pd. yang telah memberikan bimbingan dan masukan dalam penyusunan manuskrip ini.

\section{DAFTAR PUSTAKA}

Ahmadi, Farid dkk. 2017. Pengembangan Media Edukasi "Multimedia Indonesia Culture (MIC)" sebagai Penguatan Pendidikan Krakter Siswa Sekolah Dasar. Jurnal Penelitian Pendidikan. 34 (2): 1270136

Anggraini, dkk. 2019. Analisis Dampak Pemberian Reward dan Punishment bagi Siswa SD Negeri Kaliwiru Semarang. Jurnal Mimbar PGSD Undiksha. 7 (3): 221-229 ISSN: 26144735

Bakar, Ramli. 2014. The Effect of Learning Motivation on Students Productive Competencies in Vocational High School,
West Sumatra. International Journal of Asian Social Science. 4 (6): 722-732 ISSN 22244441

Haqqi, Halifa dan Hasna Wijayanti. 2019. Revolusi Industri 4.0 di tengah Society 5.0. Yogyakarta: Quadrant

Kusyairi, Umi dan Sulkipli. 2018. Meningkatkan Hasil Belajar Peserta Didik melalui Pemberian Reward dan Punishment. Jurnal Pendidikan Fisika. 6 (2): 81-88 ISSN: 25506325

Lavanya, Shylasa \& Santhosh. 2017. Industry 4.0The Fourth Industrial Revolution. International Journal of Science, Engineering and Technology Research. 6 (6) ISSN 22787798

Linh, Phan Kieu. 2019. Education in Industry 4.0. International Journal of Engineering Science Invention. 8 (6): 9-13 ISSN 2319-6734

Moleong, Lexy J. 2016. Metodologi Penelitian Kualitatif. Bandung: PT Remaja Rosdakarya

Muhasim. 2017. Pengaruh Teknologi Digital terhadap Motivasi Belajar Peserta Didik. Jurnal Studi Keislaman dan Ilmu Pendidikan. 5 (2): 53-77 ISSN 2540-9697

Peraturan Presiden Nomor 87 Tahun 2017 Penguatan Pendidikan Karakter. 2017. Jakarta: Kementrian Pendidikan Nasional

Pratiwi, Indah. 2019. Efek Program PISA terhadap Kurikulum Indonesia. Jurnal Pendidikan dan Kebudayaan. 4 (1): 51-71. Doi 10.24832/jpnk: V4/1.1157

Priambudi, Ardian. 2018. Implementasi Pendidikan Karakter di Sekolah Dasar Kecamatan Umbulharjo, Kota Yogyakarta, DIY. Jurnal Prodi Teknologi Pendidikan. 7 (2): $189-196$

Putri, Dini Palupi. 2018. Pendidikan Karakter pada Anak Sekolah Dasar di Era Digital. Jurnal Pendidikan Dasar. 2 (1): 37-50 ISSN: 2580-7946

Rachmadyanti, Putri. 2017. Penguatan Pendidikan Karakter bagi Siswa SD melalui Kearifan Lokal. Jurnal Pendidikan Sekolah Dasar. 3 (2): 201-214 ISSN 2540-9093

Raihan. 2019. Penerapan Reward and Punishment dalam Peningkatan Prestasi Belajar Pendidikan Agama Islam terhadap Siswa SMA di Kabupaten Pidie. Jounal of Islamic Education. 2 (1): 115-130 
Rifa'i, Achmad dan Cathrina Tri Anni. 2016. Psikologi Pendidikan. Semarang: Unnes Press

Sugiyono. 2016. Metode Penelitian Pendidikan (Pendekatan Kuantitatif, Kualitatif, dan R\&D. Bandung: CV Alfabeta

Suwardana, Hendra. 2017. Revolusi Industri 4.0 Berbasis Revolusi Mental. Jurnal Jati Unik. 1 (2): 102-110 ISSN: 2597-7946

Tanaya, Ina. 2019. Hasil Skor PISA Turun. http://www.kompasiana.com/hasil-skorpisa-turun-apa-korelasi-dengan-mutupendidikan (Diakses 8 Desember 2019)

Undang-Undang Dasar Republik Indonesia Tahun 1945 Pasal 31 Ayat 1 dan 2 Tentang
Pendidikan. Jakarta: Kementrian Pendidikan Nasional

Undang-Undang Republik Indonesia Nomor 20 Tahun 2003 Tentang Sistem Pendidikan Nasional. 2013. Jakarta: Kementrian Pendidikan Nasional

Vinorita, Devi \& Muhsin. 2018. Pengaruh Perhatian Orang Tua, Komunikasi Guru, Pemberian Reward dan Fasilitas Belajar terhadap Motivasi Belajar. Jurnal Pendidikan Ekonomi. 7 (2): 553-567 ISSN: 2502-356X

Wibowo, Agus. 2012. Pendidikan Karakter Strategi Membangun Karakter Bangsa Berperadaban. Yogyakarta: Pustaka Pelajar 